Article

\title{
How Does an Environmental Amenity Attract Voluntary Migrants? Evidence from Ambient Air Quality in China
}

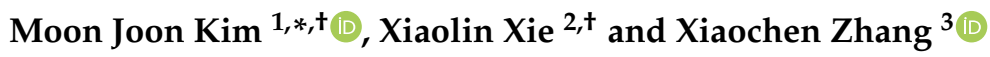 \\ 1 Energy Environment Policy and Technology, Graduate School of Energy and Environment (KU-KIST Green \\ School), Korea University, Seoul 02841, Korea \\ 2 Sanford School of Public Policy and Nicholas School of the Environment, Duke University, Durham, \\ NC 27708, USA; xiaolin.xie@duke.edu \\ 3 Division of Social Sciences, Duke Kunshan University, Kunshan 215316, China; \\ xiaochen.zhang@dukekunshan.edu.cn \\ * Correspondence: moonjoonk@gmail.com \\ + These authors contributed equally to this work.
}

check for updates

Citation: Kim, M.J.; Xie, X.; Zhang, X. How Does an Environmental Amenity Attract Voluntary Migrants? Evidence from Ambient Air Quality in China. Sustainability 2021, 13, 6872. https://doi.org/10.3390/su13126872

Academic Editor: Whanhee Lee

Received: 18 May 2021

Accepted: 14 June 2021

Published: 17 June 2021

Publisher's Note: MDPI stays neutral with regard to jurisdictional claims in published maps and institutional affiliations.

Copyright: (c) 2021 by the authors. Licensee MDPI, Basel, Switzerland. This article is an open access article distributed under the terms and conditions of the Creative Commons Attribution (CC BY) license (https:/ / creativecommons.org/licenses/by/ $4.0 /)$.

\begin{abstract}
Recent studies have shown that air quality is an important amenity for population relocation in China. However, much of Chinese internal migration occurs due to non-discretionary reasons, such as government policies, family considerations, and military personnel reassignments. As such, estimates of the impact of environmental amenities on migration that do not control for migration reasons may be biased. Using the 2015 China Migrants Dynamic Survey, this paper estimates the impact of ambient air pollution on voluntary migration to other provinces for work. We find that more polluted days (air quality index (AQI) > 150) at the original residence leads to a significant increase in labor out-migration to a province with better air quality, providing evidence of the current migration trend leading to declining populations in China's megacities. Our findings indicate that environmental migration is more favored among households that are less educated, are older, work overtime, and have lower income, suggesting that environmental migration may result from environmental health inequalities in socially disadvantaged families.
\end{abstract}

Keywords: air quality; labor migration; environmental health inequality

JEL Classification: J61; R23; Q53

\section{Introduction}

Environmental health has become an important factor in the quality of life in China as public interest in health and well-being has increased. People buy air purifiers or anti- $\mathrm{PM}_{2.5}$ face masks to prevent exposure to air pollution [1,2], temporarily leave residential areas to avoid bad air quality [3], eat locally grown or organic foods that are considered to offer more health benefits and to be more environmentally friendly $[4,5]$, and drink bottled or filtered water instead of boiled water [6]. However, if these provisional defensive behaviors do not result in better health outcomes or generate additional long-term health problems, people may ultimately seek to settle in areas with improved environmental quality [7-12], which can be described as "environmental migration" [13].

However, migration incurs substantial costs, including time, labor and transportation costs, as well as the loss of neighborhood relationships; in particular, migration in China is especially costly due to the household registration system (hukou) and the fact that migrants must abandon its benefits [14]. For example, children with a local hukou are eligible for better and more affordable education, while children who come from other areas need to bear the operating and maintenance costs of the local school. Moreover, people with the local hukou can access social insurance subsides (such as for unemployment), while people who are not local need to pay for these subsidies [15]. A floating population refers to this group of the population that migrates interprovincially without a local hukou. 
Previous literature tends to investigate migration patterns and their key amenity drivers using a floating population. Zheng et al. (2020) [16] find that interstate migration for skilled labor depends on the destination's amenities rather than job opportunities. Based on China's 2005 One-Percent Population Census data, Freeman et al. (2019) [17] find that increased $\mathrm{PM}_{2.5}$ levels have a significant negative impact on residents' utility and may increase the migration rate to other cities with better environments. Chen et al. (2017) [9] analyze migration flow data and find that poor air quality leads to decreased populations in county-level cities through decreased in-migration and increased out-migration. However, people may migrate for both discretionary and non-discretionary reasons, and if the migration decision is driven by such non-discretionary factors (e.g., relocation with relatives, migration by government policy) and this is not controlled, we argue that estimates of the impact of environmental quality on migration decisions may be biased. Therefore, our study focuses on migrants who migrate for work. These labor migrants are voluntary migrants who make their own migration decisions [18] and can also afford the high opportunity cost of giving up the local hukou.

This study contributes to the literature in four ways: First, it utilizes rich data on migrants from the 2015 China Migrants Dynamic Survey (CMDS), allowing us to identify reasons for migration. Migration occurs for many reasons, and we are able to exclude nondiscretionary and compulsory migration that occurred regardless of amenity preferences. Second, in recent literature, environmental migration has been considered an option for the well-being of highly educated and high-income individuals who reveal a high willingness to pay for clean air, but our research shows that environmental migration may be an inevitable decision for socially disadvantaged people who wish to improve their economic lives. Third, we address the potential endogeneity concern due to measurement error by using air quality information as a proxy for environmental quality and counting the seriously polluted days in a province, which is likely to minimize the spatial and geographical heterogeneities of collected air pollution levels within a region. Finally, to address the potential reverse causality that air pollution levels can be affected by population density [19-21], we focus on environmental migration from polluted areas to areas with better air quality. This approach to reverse causality considers that a lower population density results in higher levels of air pollution, which is highly unlikely in practice.

\section{Background}

\subsection{Hukou: The Chinese Household Registration System}

The hukou system was first established in 1958 to control the influx of rural migrants to cities. The primary goal of the government's hukou system was to identify and register people in two groups: the "agricultural family hukou" for those who register with the rural committee and the "non-agricultural hukou" for those who register with the urban committee. At that time, those who registered as urban residents enjoyed better social services than those with rural registration [15]. However, while rural residents could own land, urban citizens were required to borrow land from the government. Thus, in some areas, if rural councils had better incomes than councils in urban areas, people could enjoy a good annual subsidy ("fenhong") and live a better life than people holding the urban hukou. The difference between urban and rural areas decreased after the economic reform in 1978. In July 2014, the government established a unified system of hukou, called the "resident hukou," in which both rural and urban citizens could transfer their "agricultural/nonagricultural hukou" into a "resident hukou". In this way, the difference between urban and rural people was even further minimized [22].

Living in a region with a local resident hukou comes with many social benefits, such as free compulsory education for children, junior/senior high school entrance examination locations, and social security services. Thus, the greatest drawback for migrating families is that their children are not eligible for free education, including primary school and junior high school, if they do not have a local hukou. The situation is worse in megacities such as Beijing, Shanghai, Shenzhen, and Guangzhou because local children have priority for 
entering good public schools. Moreover, migrants need to pay additional operating and maintenance fees to the public school to use educational resources that were intended for local residents. In addition, migrants without a local hukou may be sent back to their hukou province for both junior and senior high school entrance examinations, although some areas have recently come to allow students who have either the local hukou or a fully local educational background ("xueji") to take the exam there.

Thus, the identification assumption in this study is that rational migrants move out of their hukou for better job opportunities or higher income as long as they can cover the opportunity cost of leaving their hukou. This means that immigrants who migrate for other reasons (e.g., government policy or family/relative issues) should not be included in research on migration patterns for environmental amenities.

\subsection{Literature}

In the previous literature, migration was seen as a process to balance people's utilities in different locations, and the utility obtained from amenities was taken into account in spatial equilibrium models [23,24]. Although job-related economic opportunities or family reunions have been cited as the primary reasons for migration, the impacts of natural amenities (e.g., presence of forest, wetlands, water, parks, trails, etc.) on migration have been well documented [25-27]. More recent research has shown that factors such as climate, temperature, and ambient air quality can also significantly affect migrants' decisions [28-30].

In particular, beyond rapid economic growth over the past decades, the desire for clean air has increased in China, and research has shown that people are willing to pay substantial amounts of money for better ambient air quality [17,31,32]. People may take temporary, short-term leave outside of their polluted areas [33] or migrate permanently to regions where they can find better ambient air quality [9,17]. Aitken (2014) [34] describes recent Chinese internal migration patterns in which wealthy residents in heavily polluted urban areas tend to migrate in search of a clean environment, while rural residents continue to flow into cities looking for work.

However, the current literature investigates environmental migration flows using floating population data that include both voluntary and forced migrants, and few studies discuss how migration decisions are made. Ascertaining the reasons for migration is important, particularly in China, because many relocation decisions are made due to non-discretionary or compulsory reasons, such as family reunions, government policy, marriage, or military personnel reassignments. Therefore, we argue that estimates that do not take into account migration reasons are biased. This study contributes to the literature by focusing on migrants who move for work and business; this type of migration results from the most discretionary migration decision.

\section{Materials and Methods}

\subsection{Data}

\subsubsection{Migration}

This study is based on 2015 China Migrants Dynamic Survey (CMDS) data from the Migrant Population Service Center of the National Health Commission of the People's Republic of China, which presents internal migration information between 2011 and 2015. The CMDS asked a question about the reason for migration, allowing us to focus on migrants who responded that they migrated "for work", which is defined in this study as "labor migration" or "migrant workers". These data also include detailed information on individual migrants, such as their socioeconomic characteristics (sex, education level, marital status, ethnicity, number of household members, and willingness to stay in their current residence for the next five years) and occupational characteristics (type of employment status, type of industry, and type of business), which may affect individuals' migration decision and migration information (the original province of residence and the destination province). 
The CMDS data have key distinctions from the One-percent Census data used in Freeman et al. (2019) [17] and Chen et al. (2017) [9]. First, our data include only floating migrants who did not have the hukou at their current residence and lived outside of their hukou for more than one month. In contrast, the census data include one percent of the population that was randomly sampled and included both local residents and floating migrants, and people had to be away from their hukou for more than six months to be considered immigrants [35]. Second, Bayer et al. (2009) [36] and Freeman et al. (2019) [17] exclude observations if the head of household is older than 35 to restrict the sample to first-time movers. However, the CMDS data already include information about whether each individual is a first-time migrant, which allows us not to lose valuable observations and more precisely target first-time movers. Last, the CMDS data include reasons for migration, which provide key information to determine whether migration is voluntary or forced.

The total number of migrants in the 2015 CMDS was 205,789. We exclude migrants who were not first-time movers, and only interprovincial migrants remained in the sample. We exclude all migrants moving to/from a foreign country to focus only on domestic migration. In addition, migration to and from Hong Kong, Macau, and Taiwan is not considered to avoid the potential impacts of public immigration policies.

Of the reasons for migration, work and business account for 76.76 percent, followed by family reunion (19.88 percent), marriage (0.63 percent), government policy ( 0.73 percent $)$, relatives and friends $(0.89$ percent $)$, education and training $(0.28$ percent $)$, military ( 0.04 percent), birth ( 0.13 percent), and others ( 0.67 percent). We focus on labor migrants who moved for work and business and exclude migrants who could have moved because of other non-voluntary factors. Also, migrants serving military service are excluded as they are required to cancel their hukou after joining the military. After we apply the above conditions, the final sample in our study is 18,342 .

Figure 1 illustrates the pattern of labor migration within mainland China over the research period (2011-2015). Panels A and B present the outflow and inflow frequencies at the provincial level, respectively. Large-scale out-migration occurred in the central provinces, including Sichuan, Henan, and Anhui, and the frequencies of inflow were high in east coast provinces (Jiangsu, Shanghai, and Zhejiang), the south (Guangdong), western provinces (Xinjiang and Tibet), and northern provinces (Beijing, Tianjin, and Heibei). This trend indicates that workforce moves out of relatively less developed central regions towards more developed and industrialized provinces in the north, east coast, and south, as well as the fastest growing economies in western provinces.

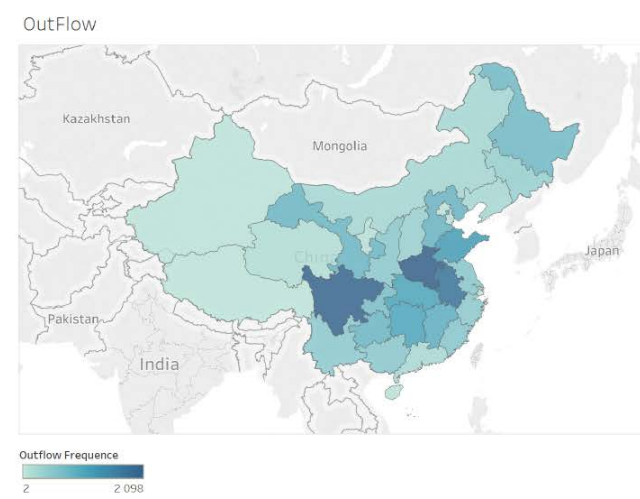

(a) Panel A: Outflows

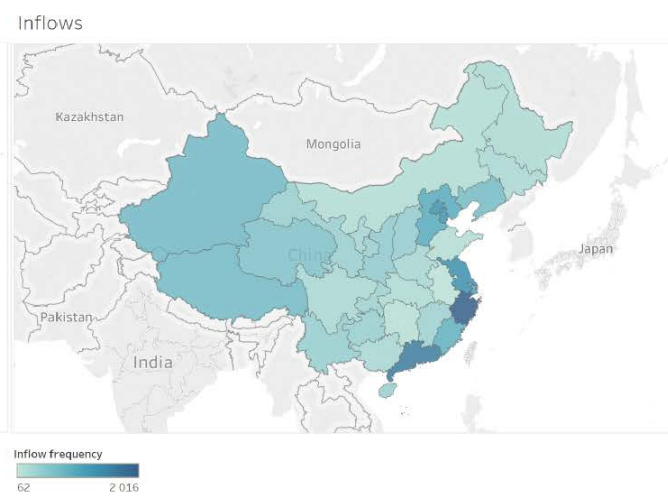

(b) Panel B: Inflows

Figure 1. Panels A and B illustrate the outflow and inflow frequencies at the provincial level between 2011 and 2015, respectively. 


\subsubsection{Air Quality Index}

The daily air quality index (AQI) is obtained from China's environmental quality database. We select 2014 as a reference year for local air quality for two reasons: First, we assume that an immigrant decides whether to move a year before the actual move takes place because migration is usually a major decision given moving and opportunity costs. For example, we assume that movement to an area with better air quality in 2015 depends on air quality information in the previous year, 2014. Therefore, we assume that a move by immigrants between 2011 and 2015 was decided upon between 2010 and 2014. Second, air quality information before 2013, measured in the air pollution index (API), did not reflect the actual local air quality due to systematic problems in air pollution measurement and incentives for data manipulation by local public officials [37,38]. Thus, the Chinese government developed and introduced the air quality index (AQI), a new index for ambient air quality, in 2013. Because of the conversion process from the API to the AQI across all of China, the national air quality information in 2013 comprises both the API and AQI that are not directly compatible.

\subsubsection{Environmental Migration}

Environmental change is a major cause of migration, along with natural disasters and economic reasons. To date, there is no universal definition of people migrating due to environmental issues [13]. Thus, the International Organization for Migration (2011) [39] suggests a working definition based on the issue's growing importance:

"Environmental migrants are persons or groups of persons who, predominantly for reasons of sudden or progressive change in the environment that adversely affects their lives or living conditions, are obliged to leave their habitual homes, or choose to do so, either temporarily or permanently, and who move either within their country or abroad."

According to the Chinese AQI standard, a day with an AQI of 150 or above is considered unhealthy (or polluted), and we count the number of polluted days (AQI > 150) in 2014 to define the environmental quality of each province. We then compare the environmental quality with the number of polluted days between the origin and destination provinces. Thus, we assume that individual $i$ will move to a new province seeking improved environmental quality if

$$
y_{i}^{P D}= \begin{cases}1 & \text { if Polluted } \mathrm{Day}_{h}-\text { Polluted } \mathrm{Day}_{j}=\triangle \mathrm{PD}_{h j}>0 \\ 0 & \text { if Polluted } \mathrm{Day}_{h}-\text { Polluted } \mathrm{Day}_{j}=\triangle \mathrm{PD}_{h j} \leq 0\end{cases}
$$

where $h$ represents the $h u k o u$ province and $j$ represents the destination province.

Figure 2 illustrates the share of environmental migration defined as $\triangle \mathrm{PD}_{h j}>0$. Of the 38,214 observations, approximately 60 percent of people $(10,935)$ moved to cleaner provinces, suggesting that more than half of migrants migrated from polluted regions to provinces with better environmental quality. In general, based on the fact that air pollution levels are more severe in more developed and industrialized cities and provinces, this result is evidence of Chinese people's interest in the quality of the environment and personal well-being in everyday life, in contrast to the theory of urbanization, where people are attracted to metropolitan cities as the economy develops. 


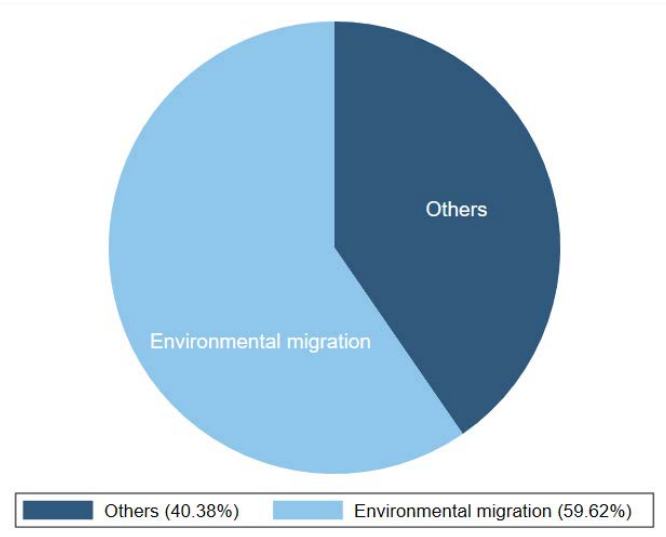

Figure 2. Environmental migration is defined as $\triangle \mathrm{PD}_{h j}>0$. Among 38,214 observations, environmental migrations account for 59.62 percent $(10,935)$, and other migrations account for 40.38 percent (7407).

\subsubsection{Descriptive Statistics}

Table 1 displays descriptive statistics of the key variables used in this study. The variables of interest are $\mathrm{PD}_{h}$ and $\mathrm{AQI}{ }_{h}$, which are the number of polluted days (AQI > $150)$ and the annual average AQI for the local hukou(h) province in 2014, respectively. The average number of polluted days in hukou provinces is 39.30, and the average number of pollution days in destination provinces is 35.99 , which indicates that people migrate to less polluted provinces.

Table 1. Descriptive statistics.

\begin{tabular}{|c|c|c|c|c|c|c|}
\hline Variable & Explanation & Obs & Mean & SD & Min & Max \\
\hline $\mathrm{PD}_{h}$ & polluted days in Hukou province $(h)$ & 18,342 & 39.30 & 24.88 & 0 & 110 \\
\hline $\mathrm{PD}_{j}$ & polluted days in destination province $(j)$ & 18,342 & 35.99 & 35.55 & 0 & 110 \\
\hline Jan_temp $p_{h}$ & temperature in January in Hukou province & 18,342 & 0.40 & 7.39 & -21.94 & 17.72 \\
\hline Jan_temp $p_{j}$ & temperature in January in destination province & 18,342 & 0.37 & 8.29 & -21.94 & 17.72 \\
\hline Jul_temp $p_{h}$ & temperature in July in Hukou province & 18,342 & 25.83 & 3.20 & 13.91 & 29.67 \\
\hline Jul_temp $j$ & temperature in July in destination province & 18,342 & 25.92 & 3.99 & 13.91 & 29.67 \\
\hline Sex & $=0$ if female $;=1$ if male & 18,342 & 0.55 & 0.50 & 0 & 1 \\
\hline Education & $\begin{array}{l}=0 \text { uneducated } ;=1 \text { primary school; } \\
=2 \text { junior high school } ;=3 \text { senior high school } \\
=4 \text { two-year college }=5 \text { college } \\
=6 \text { postgraduate }\end{array}$ & 18,342 & 2.35 & 0.97 & 0 & 6 \\
\hline Marital status & $=1$ if married $;=0$ otherwise & 18,342 & 0.65 & 0.48 & 0 & 1 \\
\hline Household income & monthly average household income (RMB) & 18,342 & 5799.67 & 5424.40 & 0 & 200,000 \\
\hline Household member & number of household members & 18,342 & 2.10 & 1.09 & 1 & 8 \\
\hline Age at migration & age of household at migration & 18,342 & 29.75 & 9.90 & 12 & 70 \\
\hline Ethnicity & $=1$ if Han Chinese $;=0$ otherwise & 18,342 & 0.9965 & 0.0590 & 0 & 1 \\
\hline Working hours & weekly working hours & 18,342 & 52.68 & 15.84 & 0 & 126 \\
\hline Social insurance & $=1$ if entitled to social insurance & 18,342 & 0.92 & 0.27 & 0 & 1 \\
\hline
\end{tabular}

Notes: The CMDS data cover 2011-2015 for 31 provinces in China (excluding Hong Kong and Macau). $h$ and $j$ represent the original residence (hukou) and the destination province, respectively. Air quality variable (PD) is based on 2014 data. Household income is measured in Chinese RMB (CNY).

This paper uses a variety of control variables, such as weather, socioeconomic, and occupational characteristics. First, the weather variables are the average temperatures in January and July in both the hukou and destination provinces. Second, the household's socioeconomic status, such as gender, education, marital status, ethnicity, age at migration, social insurance status, and working hours, as well as the number of household members and their gross income in the year of the move are included. Finally, the data contain detailed information about the household head's professional characteristics, including types of industry (mining, electricity, coal, water and heat production, real estate, public administration, social security and social organization, international organization, construction, transportation, storage and postal service, education, finance, neighborhood service, 
repair and other services, scientific technological service, agriculture, forestry, grazing and fishery, wholesale and retail industry, water conservancy, environment and public facilities management, health and social work, culture, sport and entertainment, information transmission, software and information technology service, manufacture, accommodation and catering, leasing and business services.), business (government or public institution, state-owned company, collective company, joint stock firm, Hong Kong-Macau-Taiwan wholly owned enterprise, individual business, social clubs/NGOs, private enterprise, foreign-owned company, Sino-foreign joint venture, and other), and employment status (employee, employer, self-employed, and other), which are not included in Table 1 because they are string variables.

\subsection{Empirical Methods}

\subsubsection{Migration Gravity}

Following Train (2009) [40], we exploit a random utility maximization (RUM) framework that has been applied in many previous studies to examine migrants' decisionmaking [41-44]. In this approach, individuals $i$ face a finite set of alternatives $J$ and choose destination province $j$ that maximizes their utility, which is defined as

$$
U_{i j}=V_{i j}+\epsilon_{i j}
$$

where $V_{i j}$ is a deterministic component of the utility function and $\epsilon_{i j}$ is an error term. Following McFadden [45], the logit choice probability can be constructed as follows. Individuals have the same number of alternatives $J$, and an individual migration decision maker $i$ has a higher likelihood of choosing alternative province $j$ that provides the highest utility over all $J$ choices if and only if

$$
\begin{aligned}
\operatorname{Pr}[m=j] & =\operatorname{Pr}\left[U_{i j}>U_{i k} ; \text { all } k \neq j\right] \\
& =\operatorname{Pr}\left[V_{i j}+\epsilon_{i j}>V_{i k}+\epsilon_{i k} ; \text { all } k \neq j\right] \\
& =\operatorname{Pr}\left[\epsilon_{i k}<\epsilon_{i j}+V_{i j}-V_{i k} ; \text { all } k \neq j\right]
\end{aligned}
$$

If we assume that errors are independent and identically distributed with a Type 1 extreme value distribution (IIA), then Equation (6) yields

$$
\operatorname{Pr}[m=j]=\frac{e^{V_{i j}}}{\sum_{k} e^{V_{i k}}}
$$

Then, the log-likelihood function for all individuals moving from hukou to a destination province $j$ is

$$
\ln L=\sum_{h} m_{h j} \ln P\left(m_{h j}=1\right)
$$

\subsubsection{Potential Endogeneity of Air Pollution}

The potential endogeneity of air pollution is a major concern of empirical studies examining its various effects. In general, air pollution may be endogenous because of three factors: (1) measurement error, (2) avoidance behaviors, and (3) reverse causality. Previous literature has addressed this potential endogeneity using air quality alert information [46,47], instrumental variables methods [48-52], or regression discontinuity designs [53].

In migration research, endogeneity problems of air pollution can arise primarily because of measurement errors and reverse causality. First, measurement errors are caused by spatial heterogeneity because pollution levels vary across ground-level monitors within an area of interest and by geographical heterogeneity in terms of population distribution. Using instrumental variables may help control for measurement error. However, the IV approach is not applicable in this study because migration decisions are usually made not based on daily variations but based on an overall assessment of environmental quality. In 
this study, we address the measurement error by counting the heavily polluted days in each province, which is likely to be similar within the same region because they share the same economic activities and latitude, altitude, topography, and atmospheric conditions and is especially true for severe weather conditions (e.g., heavy rains, high winds, and dust storms). Thus, using information on heavy pollution days reduces the spatial and geographical heterogeneities of air pollution levels within the region.

Second, air pollution and population density are highly correlated, and finding the causal effect of one side on the other is often difficult. To address the potential reverse causality that increased population density leads to elevated air pollution levels through various economic activities, we focus on interprovincial migrants moving for better air quality. The reverse causality in this approach is that a lower population density results in higher levels of air pollution, which is highly unlikely in practice. We also use detailed individual information, including socioeconomic and demographic characteristics (gender, education level, marital status, household income, number of household members, and age at migration), occupational characteristics (industry type, business type, and employment type), and provincial weather characteristics (January and July temperature at the destination and the difference between the origin and destination) to control for unobserved factors that might affect individuals' migration decisions.

\section{Results and Discussion}

\subsection{Baseline Results and Robustness Checks}

Table 2 reports the baseline regression results for the logit model, and each column displays the results of a separate regression with different settings for control variables and fixed effects (FE). The dependent variable is $y_{i}^{P D}$, as defined above, which equals one if a migrant migrates to a province with fewer days of heavy air pollution and zero otherwise. The key explanatory variable of interest is "Polluted day ${ }_{h}$ ", which represents the number of polluted days in a hukou province of each migrant. Robust standard errors are used in all regressions.

Table 2. The effects of ambient air pollution on environmental migration: Baseline results.

\begin{tabular}{|c|c|c|c|c|c|c|}
\hline & (1) & (2) & (3) & (4) & (5) & (6) \\
\hline \multirow[t]{2}{*}{ Polluted day $_{h}$} & $0.0240 * * *$ & $0.0187^{* * *}$ & $0.0212 * * *$ & $0.0220 * * *$ & $0.0220 * * *$ & $0.0220 * *$ \\
\hline & $(0.0008)$ & $(0.0009)$ & $(0.0009)$ & $(0.0009)$ & $(0.0009)$ & $(0.0096)$ \\
\hline \multirow{2}{*}{$\begin{array}{l}\text { Weather controls } \\
\text { Socioeconomic } \\
\text { controls }\end{array}$} & No & Yes & Yes & Yes & Yes & Yes \\
\hline & No & No & Yes & Yes & Yes & Yes \\
\hline Industry FE & No & No & No & Yes & Yes & Yes \\
\hline Business FE & No & No & No & Yes & Yes & Yes \\
\hline Employment FE & No & No & No & Yes & Yes & Yes \\
\hline Year FE & No & No & No & No & Yes & Yes \\
\hline Clustering & - & - & - & - & - & hukou \\
\hline Observations & 18,342 & 18,342 & 16,538 & 16,537 & 16,537 & 16,537 \\
\hline
\end{tabular}

Notes: Columns (1)-(6) include the coefficients and robust standard errors from the standard logit regression. Weather controls include the differences in January and July temperatures between hukou and destination provinces. Socioeconomic controls include sex, age at migration, marital status, education, number of household members, weekly working hours, social insurance status, ethnic group, and $\log$ (household income). The robust standard error in column (6) is clustered at the original hukou level to control for heteroskedasticity and within-province correlation among migrants from the same hukou. ${ }^{* * *}$ Significant at the $1 \%$ level, ${ }^{* *}$ significant at the $5 \%$ level.

Column (1) includes only the key explanatory variable, and in column (2), weather controls include differences in January and July temperatures between hukou and the destination province, as the decision to migrate may depend on the difference in weather conditions between the current province and the destination province. In column (3), socioeconomic controls include sex, age at migration, marital status, education, number of household members, weekly working hours, social insurance status, ethnic group, and household income. Household income is log-transformed to control for skewness and overdispersion. Column (4) includes fixed effects for migrants' occupational characteristics, including types of industry, business, and employment status, to control for unobserved 
heterogeneity in labor migration. We add year fixed effects in column (5) to control for moving trends or changing environmental awareness by year. The robust standard error in column (6) is clustered at the hukou level to control for heteroskedasticity and withinprovince correlation among migrants from the same hukou [54].

Our findings show significant and robust effects of ambient air pollution on environmental migration. In columns (1)-(6), an increase in the number of polluted days, defined as AQI exceeding 150, in hukou leads to a significant increase in the migration of labor to a province with better air quality. The magnitude of the estimate is significantly smaller after we control for temperature differences between the original hukou and destination provinces. Furthermore, our results indicate that excluding the socioeconomic and occupational characteristics of each migrant may lead to downward-biased estimates due to omitted variable bias. The estimate in column (6) is still statistically significant after we control for potential correlation between individuals migrating from the same hukou.

Table A1 reports the full regression results of the baseline model. D_jantemp $p_{j h}$ and $\mathrm{D}_{-}$jultemp $\mathrm{j}_{h h}$ represent the differences in average temperatures in January and July between the destination and hukou provinces, respectively. As with other conventional migrations, environmental migrants prefer to migrate to areas with warmer winters and cooler summers, and the consistency of estimates in magnitude and statistical significance across model specifications demonstrates that weather conditions play an important role in environmental migration decision making. Interestingly, the magnitude of the summer temperature difference estimate is approximately two times larger than that of the winter temperature difference, indicating that environmental migrants place greater value on cooler summers than warmer winters.

Education levels are strongly and inversely associated with environmental migration. The educational attainment level of the head of household is divided into six levels: uneducated, primary school, junior high school, senior high school, 2-year college, college or university, and postgraduate, and uneducated is omitted due to multi-collinearity. Although the effects of education on conventional labor migration are still under debate [55], our findings show that as educational attainment increases, the probability of environmental migration monotonically decreases. This indicates that highly educated people prefer more developed or industrialized areas to eco-friendly areas. Outdoor work is more prevalent among less-educated workers [56], and thus they may respond more sensitively to changes in ambient air quality. On the other hand, the literature has found a clear association between income and education level, and highly educated workers earn higher wages. However, in this paper, we find that the level of household income, unlike education level, does not have a significant effect on environmental migration.

An increase in the number of household members leads to a significant increase in the probability of migrating to a province with a better environment. This result is consistent with previous studies showing that people act in a more environmentally friendly manner as the number of household members increases, particularly when they have children [57,58]. Persistent exposure to air pollution increases health risks, and as more families are located in these areas, health and economic damages are expected to increase, resulting in a higher willingness-to-pay for better air quality [32].

Marital status has a significant impact on environmental migration. If one marries, the probability of migrating to a province with a better environment decreases. This indicates that married couples tend to migrate to more industrialized provinces if they have a spouse/dependent to support, as most developed provinces suffer from severe air pollution [59,60]. Hu [61] discusses the recent rural-urban migration trend among the young generation in China, as members of this new generation seek opportunities to move to major provinces where they may have better opportunities for employment and enjoy city life. Ethnicity and whether individuals have any social insurance do not have significant effects on environmental migration.

We then perform robustness checks, and Table 3 shows the results from using alternative clustering (column (2)), alternative fixed effects (columns (3)), and alternatively 
defined environmental migration (columns (4) and (5)). In column (2), we cluster the robust standard errors at the greater administrative area level to control for potential heteroskedasticity and correlation within larger political divisions. China's greater administrative areas consist of six divisions: North (Beijing, Tianjin, Hebei, Shanxi, and Inner Mongolia), Northeast (Liaoning, Jilin, and Heilongjiang), East (Shanghai, Jiangsu, Zhejiang, Anhui, Fujian, Jiangxi, and Shandong), South Central (Henan, Hubei, Hunan, Guangdong, Guangxi, and Hainan), Southwest (Chongqing, Sichuan, Guizhou, Yunnan, and Tibet), and Northwest (Shaanxi, Gansu, Qinghai, Ningxia, and Xinjiang). Using a larger level of clustering, we still find a positive significant estimate of polluted days in hukou with a smaller standard error than the baseline model. In column (3), we use industry-by-business fixed effects and month-by-year fixed effects to address time-invariant industry-specific shocks by business type and monthly variation in move by year, respectively. The estimate is slightly larger than the baseline model and statistically significant.

Table 3. The effects of ambient air pollution on environmental migration: Robustness checks.

\begin{tabular}{|c|c|c|c|c|c|}
\hline & $\begin{array}{c}\text { (1) } \\
\text { Baseline }\end{array}$ & $\begin{array}{c}\text { (2) } \\
\text { Alternative } \\
\text { Clustering }\end{array}$ & $\begin{array}{c}\text { (3) } \\
\text { Alternative } \\
\text { Fixed Effects }\end{array}$ & $\begin{array}{c}\text { (4) } \\
\text { Alternatively } \\
\text { Defined EM } 1 \\
(\mathrm{AQI}>100)\end{array}$ & $\begin{array}{c}(5) \\
\text { Alternatively } \\
\text { Defined EM } 2 \\
(A Q I>200)\end{array}$ \\
\hline Polluted day ${ }_{h}$ & $\begin{array}{c}0.0220 * * \\
(0.0096)\end{array}$ & $\begin{array}{c}0.0220 * * \\
(0.0092)\end{array}$ & $\begin{array}{c}0.0226 * * \\
(0.0098)\end{array}$ & $\begin{array}{c}0.0183 * * * \\
(0.0063)\end{array}$ & $\begin{array}{c}0.1125^{* * *} \\
(0.0326)\end{array}$ \\
\hline Weather controls & Yes & Yes & Yes & Yes & Yes \\
\hline Socioeconomic controls & Yes & Yes & Yes & Yes & Yes \\
\hline Industry FE & Yes & Yes & No & Yes & Yes \\
\hline Business FE & Yes & Yes & No & Yes & Yes \\
\hline Employment FE & Yes & Yes & Yes & Yes & Yes \\
\hline Industry-by-business FE & No & No & Yes & No & No \\
\hline Year FE & Yes & Yes & No & Yes & Yes \\
\hline Month-by-year FE & No & No & Yes & No & No \\
\hline Clustering & hukou & region & hukou & hukou & hukou \\
\hline Observations & 16,537 & 16,537 & 16,411 & 16,537 & 16,537 \\
\hline
\end{tabular}

Notes: Columns (1)-(5) include the coefficients and cluster-robust standard errors from the standard logit regression. Standard errors in column (2) are clustered at the greater administrative region level, including North, Northeast, East, South Central, Southwest, and Northwest. EM in columns (5) and (6) stands for environmental migration. ${ }^{* *}$ Significant at the $1 \%$ level, ${ }^{* *}$ significant at the $5 \%$ level.

In columns (4) and (5), alternative criteria are used to redefine the dependent variable, environmental migration. In the baseline model, we count the number of polluted days defined as AQI > 150, and if migrants migrated to provinces with fewer polluted days, we consider them environmental migrants. For robustness checks, we redefine the polluted days when the daily AQI level exceeds 100 (column (4)) and 200 (column (5)). AQI levels between 100 and 150 are considered "moderately polluted", and AQI levels above 200 are considered "severely polluted". In both columns, we show that an increase in polluted days in a hukou leads to a statistically significant increase in the probability of environmental migration. The magnitude of the estimate for comparing heavily polluted days in column (5) is significantly greater than the baseline model, indicating that environmental migrants respond more sensitively to a change in the number of heavy pollution days. All other control variables and fixed effects are applied the same as the baseline model.

\subsection{Heterogeneity Analysis}

There are many determinants of migration, and the tendency for environmental migration may also vary by different subgroups of populations. In this section, we split our sample by personal characteristics (sex and age) and working conditions (weekly working hours and employment type) of the head of each household and family economic levels (family income and family income per capita), and we examine the factors that may lead to a larger desire for better environmental amenities. All regressions for sensitivity analysis are based on our baseline regression model, as shown in column (6) in Table 2.

Table 4 shows the regression results for the sex and age of the head of household. We split the age of household heads into four groups: 17 and below (column 1), 18-35 
(column 2), 35-50 (column 3), and 50 and above (column 4). Panels A and B show the results for males and females, respectively. In migration studies, the effects of age on labor migration are mixed and show an inverse-U relationship due to changes in the magnitude of benefits and costs with age [55]. For male household heads, our findings show an inverse U-shaped relationship between age and environmental migration. For female household heads, however, the likelihood of environmental migration soars at older ages, indicating that older migrant women place higher value on health and the environment than younger migrant women or migrant men.

Interaction effects between women and the elderly may lead to a gender and age gap in environmental migration. Older people tend to engage more with nature and to avoid environmental damage [62], and the elderly population is more susceptible to environmental risks, including air pollution [63]. Moreover, many studies have investigated the gender gap in attitudes towards pollution, showing that women have greater concerns about environmental problems than men $[64,65]$ and are more willing to buy environmentally friendly goods [57]. Therefore, elderly female migrants are more likely to prefer environmental migration. In both panels, estimates for young household heads under the age of 17 are not statistically significant, implying that this population may need more economic opportunities than better environmental quality.

Table 4. Effects of pollution in hukou province on environmental migration: by sex and age.

\begin{tabular}{|c|c|c|c|c|}
\hline \multicolumn{5}{|l|}{ Panel A: Male } \\
\hline & $\begin{array}{c}(1) \\
17 \text { and below }\end{array}$ & $\begin{array}{c}(2) \\
18-35\end{array}$ & $\begin{array}{c}(3) \\
35-50\end{array}$ & $\begin{array}{c}(4) \\
50 \text { and above }\end{array}$ \\
\hline Polluted day ${ }_{h}$ & $\begin{array}{c}0.0087 \\
(0.0124)\end{array}$ & $\begin{array}{l}0.0197 * * \\
(0.0084)\end{array}$ & $\begin{array}{c}0.0360^{* * *} \\
(0.0096)\end{array}$ & $\begin{array}{l}0.0323 * * \\
(0.0141)\end{array}$ \\
\hline Observations & 367 & 5890 & 2515 & 442 \\
\hline \multicolumn{5}{|l|}{ Panel B: Female } \\
\hline & $\begin{array}{c}(1) \\
17 \text { and below }\end{array}$ & $\begin{array}{c}(2) \\
18-35\end{array}$ & $\begin{array}{c}(3) \\
35-50\end{array}$ & $\begin{array}{c}(4) \\
50 \text { and above }\end{array}$ \\
\hline Polluted day ${ }_{h}$ & $\begin{array}{c}0.0177 \\
(0.0139)\end{array}$ & $\begin{array}{l}0.0211^{* *} \\
(0.0102)\end{array}$ & $\begin{array}{l}0.0241^{* *} \\
(0.0102)\end{array}$ & $\begin{array}{c}0.0877^{* * *} \\
(0.0283)\end{array}$ \\
\hline Observations & 531 & 4988 & 1567 & 162 \\
\hline Weather controls & Yes & Yes & Yes & Yes \\
\hline Socioeconomic controls & Yes & Yes & Yes & Yes \\
\hline Industry FE & Yes & Yes & Yes & Yes \\
\hline Business FE & Yes & Yes & Yes & Yes \\
\hline Employment FE & Yes & Yes & Yes & Yes \\
\hline Year FE & Yes & Yes & Yes & Yes \\
\hline Clustering & hukou & hukou & hukou & hukou \\
\hline
\end{tabular}

Notes: Columns (1)-(4) include the coefficients and cluster-robust standard errors from the standard logit regression. Standard errors are clustered at the original hukou level to control for heteroskedasticity and withinprovince correlation among migrants from the same hukou. Control variables for sex and age are excluded from the regression in Panels A and B, respectively. ${ }^{* *}$ Significant at the $1 \%$ level, ${ }^{* *}$ significant at the $5 \%$ level.

Table 5 displays the regression results by working condition of the head of household. Panel A shows the effects of air pollution on environmental migration by weekly working hours, and we divide working hours into four groups depending on the severity of work hours. In China, the standard working hours of an employee are limited to $8 \mathrm{~h}$ per day or $40 \mathrm{~h}$ per week, and any work beyond the limit is considered overtime. Our results show that longer working hours increase the likelihood of environmental migration monotonically, and the estimates are statistically significant only for overtime workers (more than $40 \mathrm{~h}$ and above/week). This implies that people spending more time working (either indoors or outdoors), particularly those who work overtime, are more inclined to migrate for better environmental quality.

Panel B presents the regression results by employment type. CMDS respondents report their employment status in four types: employer, self-employed, employee, and others. We find that an increase in the number of polluted days in local hukou leads to an increase in 
the likelihood of emigrating to regions with better environmental quality for employers and self-employed people. In general, employers and self-employed individuals operate their own businesses, which allows them more discretion over their work environment than employees [66], and in response to an increase in air pollution levels, they can relocate their business sites or hire a professional local manager according to their geographic preferences. On the other hand, we also find that migration decisions for employees are not affected by changes in environmental quality in their place of origin, and this may be due to occupational determinants of geographical labor mobility.

Table 5. The effects of air pollution on environmental migration: weekly working hours and employment type.

\begin{tabular}{|c|c|c|c|c|}
\hline \multicolumn{5}{|c|}{ Panel A: Weekly working hours } \\
\hline & $(1)$ & (2) & (3) & (4) \\
\hline & $40 \mathrm{~h}$ and below & $41-50 \mathrm{~h}$ & $51-60 \mathrm{~h}$ & $61 \mathrm{~h}$ and above \\
\hline \multirow{2}{*}{ Polluted day $_{h}$} & 0.0141 & $0.0250 * *$ & $0.0294^{* * *}$ & $0.0304^{* * *}$ \\
\hline & $(0.0094)$ & $(0.0099)$ & $(0.0093)$ & $(0.0089)$ \\
\hline Employment FE & Yes & Yes & Yes & Yes \\
\hline Observations & 4566 & 3935 & 4213 & 3824 \\
\hline \multicolumn{5}{|c|}{ Panel B: Employment type } \\
\hline \multirow{4}{*}{ Polluted day $_{h}$} & (1) & $(2)$ & (3) & (4) \\
\hline & Employer & Self-employed & Employee & Others \\
\hline & $0.0436^{* * *}$ & $0.0369^{* * *}$ & 0.0154 & $0.0431^{* * *}$ \\
\hline & $(0.0138)$ & $(0.0088)$ & $(0.0096)$ & $(0.0130)$ \\
\hline Employment FE & No & No & No & No \\
\hline Observations & 1021 & 4470 & 10,777 & 207 \\
\hline Weather controls & Yes & Yes & Yes & Yes \\
\hline Socioeconomic controls & Yes & Yes & Yes & Yes \\
\hline Industry FE & Yes & Yes & Yes & Yes \\
\hline Business FE & Yes & Yes & Yes & Yes \\
\hline Year FE & Yes & Yes & Yes & Yes \\
\hline Clustering & hukou & hukou & hukou & hukou \\
\hline
\end{tabular}

Notes: Columns (1)-(4) include the coefficients and cluster-robust standard errors from the standard logit regression. Standard errors are clustered at the original hukou level to control for heteroskedasticity and within-province correlation among migrants from the same hukou. Control variables for working hours and employment type are excluded from the regression in Panels A and B, respectively. ${ }^{* *}$ Significant at the $1 \%$ level, ${ }^{* *}$ significant at the $5 \%$ level.

Table 6 summarizes the regression results by household income and household income per capita. Monthly household income is divided by the number of household members to calculate household income per capita. Following Kochar at the Pew Research Center [67] and the China Power Team [68], we separate family income and family income per capita into four ranges: low (2000 and below per household; 1500 and below per capita), lower-middle (2000-5000 per household; 1500-3000 per capita), upper-middle (5000-10,000 per household; 3000-5000 per capita), and high (above 10,000 per household; above 5000 per capita).

In Panel A, we find that the estimates increase as household income levels increase, and only lower-income and upper-middle-income households respond significantly to an increase in the number of heavy pollution days. However, Panel B presents the results by per capita household income level and shows that the estimates are larger and statistically significant for low levels of per capita household income groups in columns (1) and (2). These results suggest that low-income individual workers are more likely to be exposed to environmental hazards $[69,70]$ and may have a higher preference for clean air in choosing their residential location, although their marginal willingness to pay for clear air is estimated to be lower than individuals in high-income households [1]. 
Table 6. The effects of air pollution on environmental migration: By family income and family income per capita.

\begin{tabular}{|c|c|c|c|c|}
\hline \multicolumn{5}{|c|}{ Panel A: Household income (RMB/month) } \\
\hline & $\begin{array}{c}(1) \\
\text { Low } \\
(2000 \text { or below })\end{array}$ & $\begin{array}{l}\qquad(2) \\
\text { Lower-middle } \\
(2000-5000)\end{array}$ & $\begin{array}{c}(3) \\
\text { Upper-middle } \\
(5000-10,000)\end{array}$ & $\begin{array}{c}(4) \\
\text { High } \\
\text { (above 10,000) }\end{array}$ \\
\hline Polluted day $_{h}$ & $\begin{array}{l}0.0172 * \\
(0.0093)\end{array}$ & $\begin{array}{l}0.0210^{* *} \\
(0.0092)\end{array}$ & $\begin{array}{c}0.0243 * * \\
(0.0098)\end{array}$ & $\begin{array}{l}0.0287 * \\
(0.0149)\end{array}$ \\
\hline Observations & 766 & 8959 & 5838 & 961 \\
\hline \multicolumn{5}{|c|}{ Panel B: Household income per capita (RMB/month) } \\
\hline \multirow{4}{*}{ Polluted day $_{h}$} & $(1)$ & $(2)$ & (3) & (4) \\
\hline & $\begin{array}{c}\text { Low } \\
\text { (1500 and below) }\end{array}$ & $\begin{array}{l}\text { Lower-middle } \\
\quad(1500-3000)\end{array}$ & $\begin{array}{c}\text { Upper-middle } \\
(3000-5000)\end{array}$ & $\begin{array}{c}\text { High } \\
\text { (above 5000) }\end{array}$ \\
\hline & $0.0287^{* * *}$ & $0.0238^{* *}$ & 0.0174 * & 0.0216 \\
\hline & $(0.0084)$ & $(0.0096)$ & $(0.0091)$ & $(0.0154)$ \\
\hline Observations & 2566 & 8028 & 4521 & 1427 \\
\hline Weather controls & Yes & Yes & Yes & Yes \\
\hline Socioeconomic controls & Yes & Yes & Yes & Yes \\
\hline Industry FE & Yes & Yes & Yes & Yes \\
\hline Business FE & Yes & Yes & Yes & Yes \\
\hline Employment FE & Yes & Yes & Yes & Yes \\
\hline Clustering & hukou & hukou & hukou & hukou \\
\hline
\end{tabular}

Notes: Columns (1)-(4) include the coefficients and cluster-robust standard errors from the standard logit regression. Standard errors are clustered at the original hukou level to control for heteroskedasticity and within-province correlation among migrants from the same hukou. The control variable for household income is excluded from the regression in Panels A and B. ${ }^{* *}$ Significant at the $1 \%$ level, ${ }^{* *}$ significant at the 5\% level, * significant at the 10\% level.

\subsection{Nonlinearity}

Differences in the number of polluted days between two provinces (origin and destination) may have heterogeneous impacts on migration decision making. To examine these nonlinear effects by the size of the differences, we categorize 10 groups in order based on the differences in the number of polluted days: $[-110,-66]$ (extremely clean); $[-66,-44]$ (very clean); [-44, -22] (clean); [-22, 0) (moderately clean); [=0] (indifferent); (0-22] (moderately polluted); [22-44] (polluted); [44-66] (very polluted); and [66, 110] (extremely polluted)]. For this, an ordered logit model is used to estimate the impacts of the gap in the number of polluted days between two provinces on the decision-making process:

$$
\operatorname{Pr}[y=j]=\frac{e^{V_{j}}}{1+\sum_{i=1}^{J-1} e^{V_{i}}}
$$

Figure 3 illustrates the regression results from the ordered logit model using the difference in the number of polluted days. We measure the marginal effects of the number of polluted days at the origin location on different levels of environmental migration while keeping all other covariates constant at their means. The results on the left-hand side of zero show that people most prefer to migrate to places where the number of polluted days is 22-66 days less per year than that in their current hukou. If the difference in the number of days of pollution is greater than 66 days, the coefficients become small in magnitude and turn out to be statistically insignificant. This indicates that people do not pursue living in extremely cleaner areas, which may be remote rural or underdeveloped areas. If an area has a higher number of polluted days than the current hukou, shown on the right-hand side of zero, our regression yields negative probabilities across all ranges, indicating that people are less likely to migrate to regions with poorer ambient air quality. 


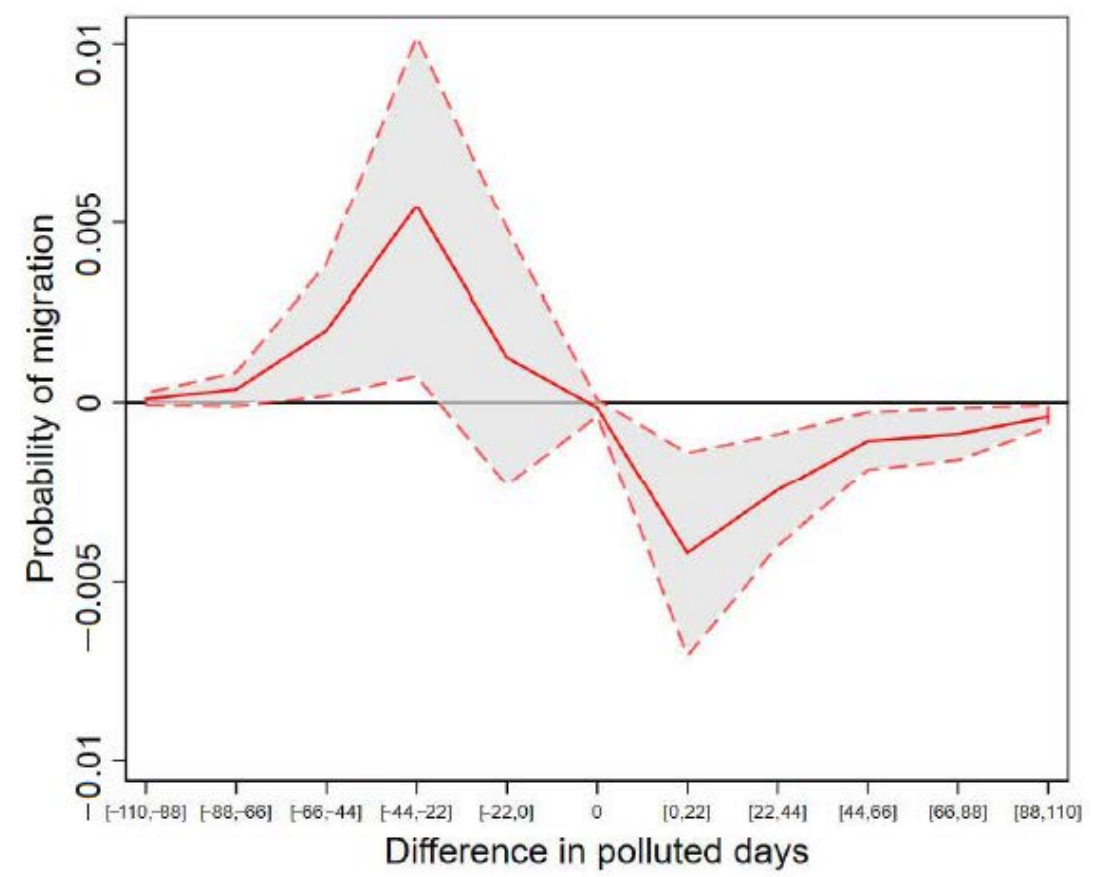

Figure 3. Each bin represents the 22-interval differences in the number of days with AQI exceeding 150 between the original hukou and the destination provinces.

\subsection{Environmental Migration and Environmental Health Inequalities}

Environmental migration may result from environmental inequality arising from socio-environmental vulnerability. Environmental risks are not evenly distributed across the population, and some groups with older, low-income, and ethnic minority status generally face disproportionately high risks of environmental diseases [69]. As exposure to harmful working conditions is strongly associated with the skill level of workers, these groups are more likely to encounter high environmental health risks in the workplace [70].

Furthermore, China's rapid economic development in recent decades has caused serious income inequality across the country. Wealthy urban dwellers buy apartments and homes for investment, which drives housing prices sky-high and causes socially disadvantaged groups to live in poorer residential conditions. Poor living conditions, high rents, and high living expenses eventually force them to move to other regions. Therefore, these socially disadvantaged groups may seek better environmental quality in choosing their next residential location, which leads to positive and statistically significant estimates of environmental migration.

Last, our results are statistically significant only for employers and self-employed people because of their flexible occupational mobility. In the case of employees, the estimates are positive but statistically insignificant, suggesting that employees cannot adequately respond to poor air quality due to lack of mobility. We would expect the damage from environmental health inequality to be even larger if we could take into account the employee population.

\section{Conclusions}

This paper uses ambient air pollution levels to investigate the impact of environmental quality on the decision to migrate in China. Although the research questions have been explored elsewhere, our research presents strong evidence of environmental migration using novel data from which we extract voluntary migrants and empirical approaches to address the potential endogeneity of air pollution.

The main contribution of this study is that it focuses on migrant workers who can make a voluntary migration decision. Based on detailed information of 18,342 individuals from a census survey on migration, this paper shows that poorer air quality leads to labor 
out-migration, implying that environmental quality has become an important attribute of migration. However, note that these labor migrants move primarily for work, so potential higher income remains the priority criterion in their decision making. Nevertheless, if all else is constant, people will migrate to a region with improved environmental quality, and migration can therefore be considered a defensive behavior in response to poor air quality in the long term.

Our findings provide important policy implications, especially for developing countries experiencing rapid economic growth. Rapid economic growth increases the wealthy population, but growing economic inequalities occur simultaneously, leaving socially vulnerable populations to lag behind and suffer from poor living and working conditions. Unless the central or local governments devote more effort to reducing income inequalities, environmental health inequality caused by income inequalities will deteriorate and cause various social and economic problems. The main socially vulnerable groups are low-educated workers, and the outflow of cheap labor increases expenses for the labor force of existing companies and factories, which in turn will decrease the competitiveness of firms. Thus, more support for socially disadvantaged populations will prevent them from leaving their current residences, and businesses can reduce their labor costs.

Although the results of this paper are robust, there are several limitations that need to be addressed in future research. First, this study relies on interprovincial migration data and cannot measure migration within provinces. Differences between cities in the same province are sometimes great. For example, in Hebei, Zhangjiakou is among the top ten cities with the best air quality, while Shijiazhuang is among the cities with the poorest air quality in China. Second, the survey data used in this study do not include information on migrants prior to their migration, such as their previous occupations and income levels. Therefore, we cannot compare the differences in these variables before and after migration. Finally, due to data limitations, this study uses air pollution information from 2014 as a reference for analyzing the migration patterns from 2011-2015. This issue will be addressed if we replicate the study using more recent census data.

Author Contributions: Conceptualization, X.X.; methodology, X.X. and M.J.K.; software, M.J.K.; validation, M.J.K.; formal analysis, X.X. and M.J.K.; investigation, X.X.; resources, X.X.; data curation, X.X. and M.J.K.; writing—original draft preparation, X.X. and M.J.K.; writing-review and editing, M.J.K and X.Z.; visualization, X.X. and M.J.K.; supervision, M.J.K.; project administration, M.J.K. All authors have read and agreed to the published version of the manuscript.

Funding: This research received no external funding.

Institutional Review Board Statement: Ethical review and approval were waived for this study, due to the use of de-identified migration data.

Informed Consent Statement: Not applicable.

Data Availability Statement: Restrictions apply to the availability of these data. Data was obtained from the Migrant Population Service Center of the National Health Commission of the People's Republic of China and are available [https: / / chinaldrk.org.cn/, accessed on 6 November 2019.] with the permission of the Migrant Population Service Center.

Acknowledgments: We thank Roger von Haefen, Walter Thurman, and conference participants at the 2020 ASHEcon Virtual Conference, the WEAI annual conference SF 2019 and ISEE-ISES AC 2019 for their helpful comments. We thank Shunyu (Blake) Yan, Colleen Siv, Zhaozhi Li, and Danyang Shi for their excellent research assistance.

Conflicts of Interest: The authors declare no conflict of interest. 


\section{Appendix A}

Table A1. The effects of ambient air pollution on environmental migration: Full baseline results.

\begin{tabular}{|c|c|c|c|c|c|c|}
\hline & (1) & (2) & (3) & (4) & (5) & (6) \\
\hline \multirow[t]{2}{*}{ Pollution $_{h}$} & $0.0240^{* * *}$ & $0.0187^{* * *}$ & $0.0212^{* * *}$ & $0.0220^{* * *}$ & $0.0220^{* * *}$ & 0.0220 ** \\
\hline & $(0.0008)$ & $(0.0009)$ & $(0.0009)$ & $(0.0009)$ & $(0.0009)$ & $(0.0096)$ \\
\hline \multirow[t]{2}{*}{ D_jantemp $_{j h}$} & & $0.1390 * * *$ & $0.1411^{* * *}$ & $0.1415^{* * *}$ & $0.1415^{* * *}$ & $0.1415^{* * *}$ \\
\hline & & $(0.0033)$ & $(0.0036)$ & $(0.0036)$ & $(0.0036)$ & $(0.0384)$ \\
\hline \multirow[t]{2}{*}{ D_jultemp $_{j h}$} & & $-0.2536^{* * *}$ & $-0.2478^{* * *}$ & $-0.2782^{* * *}$ & $-0.2788^{* * *}$ & $-0.2788^{* * *}$ \\
\hline & & $(0.0058)$ & $(0.0061)$ & $(0.0067)$ & $(0.0067)$ & $(0.0770)$ \\
\hline \multirow[t]{2}{*}{ Age at migration } & & & -0.0023 & 0.0010 & 0.0008 & 0.0008 \\
\hline & & & $(0.0024)$ & $(0.0024)$ & $(0.0024)$ & $(0.0057)$ \\
\hline \multirow[t]{2}{*}{ Male } & & & -0.0167 & $-0.0854^{* *}$ & $-0.0862 * *$ & $-0.0862 *$ \\
\hline & & & $(0.0373)$ & $(0.0391)$ & $(0.0391)$ & $(0.0462)$ \\
\hline \multicolumn{7}{|l|}{ Education } \\
\hline \multirow[t]{2}{*}{ - primary school } & & & $-0.4521^{* * *}$ & $-0.3728^{* *}$ & $-0.3697^{* *}$ & $-0.3697^{* *}$ \\
\hline & & & $(0.1612)$ & $(0.1579)$ & $(0.1580)$ & $(0.1815)$ \\
\hline \multirow[t]{2}{*}{ - junior high school } & & & $-0.8025^{* * *}$ & $-0.6434^{* * *}$ & $-0.6359 * * *$ & $-0.6359 * * *$ \\
\hline & & & $(0.1555)$ & $(0.1526)$ & $(0.1527)$ & $(0.2432)$ \\
\hline \multirow[t]{2}{*}{ - senior high school } & & & $-0.9714^{* * *}$ & $-0.7027^{* * *}$ & $-0.6882^{* * *}$ & $-0.6882^{* * *}$ \\
\hline & & & $\begin{array}{c}(0.1593) \\
-1.2876^{* * *}\end{array}$ & $\begin{array}{c}(0.1569) \\
-0.9961 * *\end{array}$ & $\begin{array}{c}(0.1571) \\
-0.9762^{* * *}\end{array}$ & $\begin{array}{c}(0.2350) \\
-0.9762 * * *\end{array}$ \\
\hline \multirow[t]{2}{*}{ - college or university } & & & $\begin{array}{c}(0.1694) \\
-1.2444 * * *\end{array}$ & $\begin{array}{c}(0.1687) \\
-1.0335 * * *\end{array}$ & $\begin{array}{c}(0.1689) \\
-1.0084 * *\end{array}$ & $\begin{array}{c}(0.2512) \\
-1.0084 * * *\end{array}$ \\
\hline & & & $(0.1824)$ & $(0.1846)$ & $(0.1850)$ & $(0.2780)$ \\
\hline \multirow[t]{2}{*}{ - postgraduate } & & & $-1.4171^{* * *}$ & $-1.3280^{* * *}$ & $-1.3240^{* * *}$ & $-1.3240^{* * *}$ \\
\hline & & & $(0.3248)$ & $(0.3259)$ & $(0.3278)$ & $(0.4546)$ \\
\hline \multirow[t]{2}{*}{$\log ($ Household income $)$} & & & $0.0879 * *$ & 0.0606 & $0.0689 *$ & 0.0689 \\
\hline & & & $(0.0388)$ & $(0.0405)$ & $(0.0406)$ & $(0.0799)$ \\
\hline \multirow[t]{2}{*}{ Household members } & & & $0.0724^{* * *}$ & $0.1401^{* * *}$ & $0.1468^{* * *}$ & $0.1468^{* * *}$ \\
\hline & & & $(0.0205)$ & $(0.0218)$ & $(0.0220)$ & $(0.0317)$ \\
\hline \multirow[t]{2}{*}{ Working hours } & & & $0.0066^{* * *}$ & $0.0085^{* * *}$ & $0.0083^{* * *}$ & $0.0083^{* * *}$ \\
\hline & & & $(0.0012)$ & $(0.0012)$ & $(0.0012)$ & $(0.0028)$ \\
\hline \multirow[t]{2}{*}{ Married } & & & $-0.4300^{* * *}$ & $-0.4203^{* * *}$ & $-0.4100^{* * *}$ & $-0.4100^{* * *}$ \\
\hline & & & $(0.0530)$ & $(0.0548)$ & $(0.0551)$ & $(0.1139)$ \\
\hline \multirow[t]{2}{*}{ Han Chinese } & & & $0.5827^{* *}$ & $0.7181^{* * *}$ & $0.7006^{* *}$ & 0.7006 \\
\hline & & & $(0.2654)$ & $(0.2767)$ & $(0.2742)$ & $(0.5286)$ \\
\hline \multirow[t]{2}{*}{ Social insurance } & & & -0.0755 & $-0.1538 * *$ & $-0.1537^{* *}$ & -0.1537 \\
\hline & & & $(0.0717)$ & $(0.0732)$ & $(0.0732)$ & $(0.1524)$ \\
\hline Industry FE & No & No & No & Yes & Yes & Yes \\
\hline Business FE & No & No & No & Yes & Yes & Yes \\
\hline Employment FE & No & No & No & Yes & Yes & Yes \\
\hline Year FE & No & No & No & No & Yes & Yes \\
\hline Clustering & - & - & - & - & - & hukou \\
\hline Observations & 18,342 & 18,342 & 16,538 & 16,537 & 16,537 & 16,537 \\
\hline
\end{tabular}

Notes: Columns (1)-(6) include the coefficients and robust standard errors from the standard logit regression. The robust standard error in column (6) is clustered at the original hukou level to control for heteroskedasticity and within-province correlation among migrants from the same hukou. ${ }^{* * *}$ Significant at the $1 \%$ level, ${ }^{* *}$ significant at the $5 \%$ level, ${ }^{*}$ significant at the $10 \%$ level. 


\section{References}

1. Ito, K.; Zhang, S. Willingness to Pay for Clean Air: Evidence from Air Purifier Markets in China. J. Political Econ. 2020, 128, 1627-1672. [CrossRef]

2. Zhang, J.; Mu, Q. Air pollution and defensive expenditures: Evidence from particulate-filtering facemasks. J. Environ. Econ. Manag. 2018, 92, 517-536. [CrossRef]

3. Chen, S.; Chen, Y.; Lei, Z.; Tan-Soo, J. Chasing Clean Air: Pollution-Induced Travels in China. J. Environ. Econ. Manag. 2021, 8, 59-89. [CrossRef]

4. Sheng, J.; Shen, L.; Qiao, Y.; Yu, M.; Fan, B. Market trends and accreditation systems for organic food in China. Trends Food Sci. Technol. 2009, 20, 396-401. [CrossRef]

5. Sirieix, L.; Kledal, P.R.; Sulitang, T. Organic food consumers' trade-offs between local or imported, conventional or organic products: A qualitative study in Shanghai. Int. J. Consum. Stud. 2011, 35, 670-678. [CrossRef]

6. Cohen, A.; Zhang, Q.; Luo, Q.; Tao, Y.; Colford, J.M., Jr.; Ray, I. Predictors of Drinking Water Boiling and Bottled Water Consumption in Rural China: A Hierarchical Modeling Approach. Environ. Sci. Technol. 2017, 52, 6945-6956. [CrossRef]

7. Banzhaf, H.S.; Walsh, R.P. Do people vote with their feet? An empirical test of Tiebout. Am. Econ. Rev. 2008, 98, 843-863. [CrossRef]

8. Cameron, T.A.; McConnaha, I.T. Evidence of environmental migration. Land Econ. 2006, 82, 273-290. [CrossRef]

9. Chen, S.; Oliva, P.; Zhang, P. The Effect of Air Pollution on Migration: Evidence from China. NBER Work. Pap. 2017, 24036. [CrossRef]

10. Finney, M.M.; Goetzke, F.; Yoon, M.J. Income sorting and the demand for clean air: Evidence from Southern California. Land Econ. 2011, 87, 19-27. [CrossRef]

11. Massey, D.S.; Axinn, W.G.; Ghimire, D.J. Environmental change and out-migration: Evidence from Nepal. Popul. Environ. 2010, 32, 109-136. [CrossRef] [PubMed]

12. Xu, X.; Sylwester, K. Environmental Quality and International Migration. Kyklos 2016, 69, 157-180. [CrossRef]

13. Dun, O.V.; Gemenne, F. Defining 'environmental migration'. Forced Migr. Rev. 2008, 31, 10-11.

14. Kinnan, C.; Wang, S.-Y.; Wang, Y. Access to Migration for Rural Households. Am. Econ. J. Appl. Econ. 2018, 10, 1-43. [CrossRef]

15. Chen, Y.; Shi, S.; Tang, Y. Valuing the Urban Hukou in China: Evidence from a Regression Discontinuity Design in Housing Price. J. Dev. Econ. 2019, 141, 102381. [CrossRef]

16. Zheng, Y.; Zhang, X.; Dai, Q.; Zhang, X. To Float or Not to Float? Internal Migration of Skilled Laborers in China. Int. J. Environ. Res. Public Health 2020, 17, 9075. [CrossRef]

17. Freeman, R.; Liang, W.; Song, R.; Timmins, C. Willingness to pay for clean air in China. J. Environ. Econ. Manag. 2019, 94, 188-216. [CrossRef]

18. Razum, O.; Samkange-Zeeb, F. Populations at Special Health Risk: Migrants. In International Encyclopedia of Public Health; Academic Press: New York, NY, USA, 2008; pp. 233-241, ISBN 9780123739605.

19. Wang, G.; Shi, X.; Cui, H.; Jiao, J. Impacts of Migration on Urban Environmental Pollutant Emissions in China: A Comparative Perspective. Chin. Geogr. Sci. 2020, 30, 48-58. [CrossRef]

20. Shi, G.; Lu, X.; Deng, Y.; Urpelainen, J.; Liu, L.C.; Zhang, Z.; Wei, W.; Wang, H. Air Pollutant Emissions Induced by Population Migration in China. Environ. Sci. Technol. 2020, 54, 6308-6318. [CrossRef] [PubMed]

21. Rafiq, S.; Nielsen, I.; Smyth, R. Effect of internal migration on the environment in China. Energy Econ. 2017, 64, 31-44. [CrossRef]

22. Zhou, S.; Cheung, M. Hukou system effects on migrant children's education in China: Learning from past disparities. Int. Soc. Work 2017, 60, 1327-1342. [CrossRef]

23. Graves, P.E. Migration and climate. J. Reg. Sci. 1980, 20, 227-237. [CrossRef] [PubMed]

24. Graves, P.E.; Linneman, P.D. Household migration: Theoretical and empirical results. J. Urban Econ. 1979, 6, 383-404. [CrossRef]

25. Chi, G.; Marcouiller, D.W. Natural amenities and their effects on migration along the urban-rural continuum. Ann. Reg. Sci. 2013, 50, 861-883. [CrossRef]

26. Cordell, K.H.; Heboyan, V.; Santos, F.; Bergstrom, J.C. Natural amenities and rural population migration: A technical document supporting the Forest Service 2010 RPA Assessment. In General Technical Reports SRS-146; Department of Agriculture Forest Service, Southern Research Station: Asheville, NC, USA, 2013; 23p.

27. Winters, J.V.; Li, Y. Urbanization, Natural Amenities, and Subjective Well-Being: Evidence from U.S. Counties. Urban Stud. 2017, 54, 1956-1973. [CrossRef]

28. Su, Y.; Hua, Y.; Liang, X. Toward Job or Amenity?: Evaluating the Locational Choice of Internal Migrants in China. Int. Reg. Sci. Rev. 2019, 42, 400-430. [CrossRef]

29. Wang, Z.; Chen, L. Destination Choices of Chinese Rural-Urban Migrant Workers: Jobs, Amenities and Local Spillovers. J. Reg. Sci. 2019, 59, 586-609. [CrossRef]

30. Sun, C.; Zheng, S.; Wang, J.; Kahn, M.E. Does Clean Air Increase the Demand for the Consumer City? Evidence from Beijing. J. Reg. Sci. 2019, 59, 409-434. [CrossRef]

31. Peng, N.; Sang-Ho, L. Estimating the Young Generation's Willingness to Pay (WTP) for PM 2.5 Control in Daegu, Korea, and Beijing, China. Sustainability 2019 11, 5704.

32. Wang, H.; Mullahy, J. Willingness to pay for reducing fatal risk by improving air quality: A contingent valuation study in Chongqing, China. Sci. Total Environ. 2006, 367, 50-57. [CrossRef] 
33. Cui, C.; Wang, Z.; He, P.; Yuan, S.; Niu, B.; Kang, P.; Kang, C. Escaping from pollution: The effect of air quality on inter-city population mobility in China. Environ. Res. Lett. 2019, 14, 124025. [CrossRef]

34. Aitken, E. Rich China's clean air migration. The Austrailian Business Review, 6 March 2014.

35. Aunan, K.; Wang, S. Internal migration and urbanization in China: Impacts on population exposure to household air pollution (2000-2010). Sci. Total Environ. 2014, 481, 186-195. [CrossRef]

36. Bayer, P.; Keohane, N.; Timmins, C. Migration and hedonic valuation: The case of air quality. J. Environ. Econ. Manag. 2009, 58, 1-14. [CrossRef]

37. Ghanem, D.; Zhang, J. ‘Effortless Perfection:' Do Chinese cities manipulate air pollution data? J. Environ. Econ. Manag. 2014, 68, 203-225. [CrossRef]

38. Zheng, S.; Cao, C.-X.; Singh, R.P. Comparison of ground based indices (API and AQI) with satellite based aerosol products. Sci. Total Environ. 2014, 488-489, 398-412. [CrossRef]

39. International Organization for Migration. Glossary on Migration. In International Migration Law; International Organization for Migration: Geneva, Switzerland, 2011.

40. Train, K.E. Discrete Choice Methods with Simulation, 2nd ed.; Cambridge University Press: Cambridge, UK, 2012. [CrossRef]

41. Davies, P.S.; Greenwood, M.J.; Li, H. A Conditional Logit Approach to U.S. State-to-State Migration. J. Reg. Sci. 2001, 41, 337-360. [CrossRef]

42. Marchal, L.; Naiditch, C. A Micro-Founded Theory of Multilateral Resistance to Migration; Kiel Working Paper No. 2051; Kiel Institute for the World Economy: Kiel, Germany, 2016.

43. Nowotny, K.; Pennerstorfer, D. Network migration: Do neighbouring regions matter? Reg. Stud. 2019, 53, 107-117. [CrossRef]

44. Beine, M.; Bertoli, S.; Fernández-Huertas Moraga, J. A Practitioners' Guide to Gravity Models of International Migration. World Econ. 2016, 39, 496-512. [CrossRef]

45. McFadden, D. Conditional Logit Analysis of Qualitative Choice Behavior. In Frontiers in Econometrics; Academic Press: New York, NY, USA, 1974; pp. 105-142, ISBN 0-12-776150-0.

46. Neidell, M. Information, Avoidance Behavior, and Health: The Effect of Ozone on Asthma Hospitalizations. J. Hum. Resour. 2009, 44, 450-478. [CrossRef]

47. Kim, M.J. Air Pollution, Health, and Avoidance Behavior: Evidence from South Korea. Environ. Resour. Econ. 2021, 79, 63-91. [CrossRef]

48. Chay, K.Y.; Greenstone, M. The impact of air pollution on infant mortality: Evidence from geographic variation in pollution shocks induced by a recession. Q. J. Econ. 2003, 118, 1121-1167. [CrossRef]

49. Cole, M.A.; Elliott, R.J.R.; Fredriksson, P.G. Endogenous Pollution Havens: Does FDI Influence Environmental Regulations? Scand. J. Econ. 2006, 108, 157-178. [CrossRef]

50. Deryugina, T.; Heutel, G.; Miller, N.H.; Molitor, D.; Reif, J. The Mortality and Medical Costs of Air Pollution: Evidence from Changes in Wind Direction. Am. Econ. Rev. 2019, 109, 4178-4219. [CrossRef] [PubMed]

51. Sager, L. Estimating the effect of air pollution on road safety using atmospheric temperature inversion. J. Environ. Econ. Manag. 2019, 98, 102250. [CrossRef]

52. Sun, C.; Zhang, W.; Fang, X.; Gao, X.; Xu, M. Urban public transport and air quality: Empirical study of China cities. Energy Policy 2019, 135, 110998. [CrossRef]

53. Huang, W.; Wang, H.; Wei, Y. Endogenous or Exogenous? Examining Trans-Boundary Air Pollution by Using the Air Quality Index (AQI): A Case Study of 30 Provinces and Autonomous Regions in China. Sustainability 2018, 10, 4220. [CrossRef]

54. Gormley, T.A.; Matsa, D.A. Common Errors: How to (and Not to) Control for Unobserved Heterogeneity. Rev. Financ. Stud. 2014, 27, 617-661. [CrossRef]

55. Lu, M.; Xia, Y. Migration in the People's Republic of China; ADBI Working Paper 593; Asian Development Bank Institute: Tokyo, Japan, 2016. Available online: https:/ / www.adb.org/publications/migration-people-republic-china (accessed on 5 March 2021).

56. Hahn, I.H.; Grynderup, M.B.; Dalsgaard, S.B.; Thomsen, J.F.; Hansen, Å.M.; Kærgaard, A.; Kærlev, L.; Mors, O.; Rugulies, R.; Mikkelsen, S.; et al. Does outdoor work during the winter season protect against depression and mood difficulties? Scand. J. Work. Environ. Health 2011, 37, 446-449. [CrossRef] [PubMed]

57. Laroche, M.; Bergeron, J.; Barbaro-Forle, G. Targeting consumers who are willing to pay more for environmentally friendly products. J. Consum. Mark. 2001, 18, 503-520. [CrossRef]

58. Loureiro, M.L.; Mccluskey, J.J.; Mittelhammer, R.C. Will Consumers Pay a Premium for Eco-labeled Apples? J. Consum. Aff. 2002, 36, 203-219. [CrossRef]

59. Han, L.; Zhou, W.; Li, W.; Li, L. Impact of urbanization level on urban air quality: A case of fine particles $\left(\mathrm{PM}_{2.5}\right)$ in Chinese cities. Environ. Pollut. 2014, 194, 163-170. [CrossRef]

60. Wang, Y.; Ying, Q.; Hu, J.; Zhang, H. Spatial and temporal variations of six criteria air pollutants in 31 provincial capital cities in China during 2013-2014. Environ. Int. 2014, 73, 413-422. [CrossRef] [PubMed]

61. Hu, X. China's 'New Generation' Rural-Urban Migrants: Migration Motivation and Migration Patterns. Migr. Inf. Source 2012. [CrossRef]

62. Wiernik, B.M.; Ones, D.S.; Dilchert, S. Age and environmental sustainability: A meta-analysis. J. Manag. Psychol. 2013, 28, 826-856. [CrossRef] 
63. Zeng, Y.; Gu, D.; Purser, J.; Hoenig, H.; Christakis, N. Associations of environmental factors with elderly health and mortality in China. Am. J. Public Health 2010, 100, 298-305. [CrossRef]

64. Xiao, C.; McCright, A.M. Explaining Gender Differences in Concern about Environmental Problems in the United States. Soc. Nat. Resour. 2012, 25, 1067-1084. [CrossRef]

65. Pearson, A.R.; Ballew, M.T.; Naiman, S.; Schuldt, J.P. Race, Class, Gender and Climate Change Communication. In Oxford Research Encyclopedia of Climate Science; Oxford University Press: Oxford, UK, 2017.

66. Parasuraman, S.; Simmers, C.A. Type of employment, work-family conflict and well-being: A comparative study. J. Organ. Behav. 2001, 22, 551-568. [CrossRef]

67. Kochar, R. A Global Middle Class Is More Promise than Reality; Pew Research Center: Washington, DC, USA, 2015.

68. China Power Team. How Well-off is China's Middle Class? China Power. 26 April 2017. Updated 29 October 2020. Available online: https: / / chinapower.csis.org/china-middle-class / (accessed on 4 February 2021).

69. Gochfeld, M.; Burger, J. Disproportionate exposures in environmental justice and other populations: The importance of outliers. Am. J. Public Health 2011, 101, S53-S63. [CrossRef] [PubMed]

70. WHO. Environment and Health Risks: A Review of the Influence and Effects of Social Inequalities; WHO Regional Office for Europe: Copenhagen, Denmark, 2010. Available online: https://www.euro.who.int/_data/assets/pdf_file/0003/78069/E93670.pdf (accessed on 5 March 2021). 